ArtefaCToS. Revista de estudios de la ciencia y la tecnología

eISSN: 1989-3612

Vol. 7, No. 1 (2018), 2a Época, 99-120

DOI: http://dx.doi.org/10.14201/art20187199120

\title{
Hacia una ética para el mundo tecnológico
}

\section{Towards an Ethics for the Technological World}

\author{
Jorge LINARES \\ Universidad Nacional Autónoma de México \\ lisjor@unam.mx
}

Recibido: 09/01/2018. Revisado: 15/01/2018. Aceptado: 24/01/2018

\begin{abstract}
Resumen
Este artículo sintetiza y actualiza, en parte, lo que he desarrollado en el libro Ética y mundo tecnológico (2008). La tesis central es que el mundo tecnológico actual es en un sistema global de dominio sobre la naturaleza y sobre la sociedad; una red de sistemas técnicos que interactúan incrementando la complejidad de las interrelaciones y el alcance espaciotemporal de sus efectos, porque está gobernado por una razón tecnocientífica uniforme y basada en una nueva "fuerza mayor". Por ello, es necesario analizar y repensar las condiciones y estructuras del mundo tecnológico en el que vivimos, así como cuestionar su racionalidad e imperativo tecnológico de transformación y dominación de todos los objetos naturales o técnicos. Los proyectos tecnológicos pueden ser reorientados o modificados si implican riesgos mayores para la naturaleza y para la vida humana. Por ello, es necesario y factible reconstruir una ética para el mundo tecnológico. Se exponen brevemente los cuatro principios fundamentales de una ética que evalúe los efectos del poder tecnológico: responsabilidad social, precaución, justicia distributiva y autonomía individual y comunitaria.
\end{abstract}

Palabras clave: ética; mundo tecnológico; tecnociencia; razón tecnocientífica; riesgos tecnológicos. 


\begin{abstract}
This article synthesizes and updates, in part, what I have developed in the book Ethics and Technological World (2008). The central thesis is that the current technological world has become a global system of dominance over nature and society; It is a network of technical systems that interact by increasing the complexity of interrelations and their temporal and geographical effects, because it is governed by a uniform techno-scientific reason, based on the new "force majeure". Therefore, it is necessary to analyze and rethink the conditions and structures of the technological world in which we live, as well as to question its rationality and technological imperative of transformation and domination of all natural or technical objects. Technological projects can be reoriented or modified if they involve greater risks to nature and human life. To do this, it is necessary and achievable to rebuild an ethics for the technological world. The four fundamental principles of that ethics that assesses the effects of technological power are briefly exposed: social responsibility, precaution, distributive justice and individual and communitarian autonomy.
\end{abstract}

Keywords: Ethics; Technological World; Technoscience; Techno-Scientific Reason; Technological Risks.

\title{
1. Introducción
}

Lo que sigue es una síntesis y actualización, en parte, de lo que he expuesto en mi libro Ética y mundo tecnológico (Linares, 2008). La tecnología contemporánea se ha convertido en el factor determinante de la praxis social, y en horizonte de las relaciones cognitivas y pragmáticas entre el ser humano y su mundo, porque es mucho más que un conjunto de instrumentos y sistemas técnicos; constituye más bien un sistema global en expansión, una red de sistemas técnicos (que funciona a través de mediaciones informáticas y una red de telecomunicaciones y transportes) que interactúan incrementando la complejidad de las interrelaciones tecnológicas y el alcance global de sus efectos sobre la naturaleza y la sociedad. El próximo nivel de interacción entre artefactos, sistemas técnicos y agentes humanos anticipa ya una cuarta revolución industrial que interconectará con el intercambio de información, acción y conocimiento, mediante inteligencia artificial, a los artefactos y a los agentes humanos (Schwab, 2016). Por ello, la extensión del poder tecnológico ha transformado también la autocomprensión del ser humano (tanto de su propia naturaleza como de sus relaciones con el mundo natural), convirtiéndolo ya en el objeto principal de ese gran proyecto de transformación ontológica del mundo.

Sin embargo, no poseemos actualmente categorías adecuadas para efectuar una exhaustiva evaluación ética del mundo tecnológico. Se ha generado una dis- 
crepancia entre el poder tecnológico y nuestra conciencia ética, pues dicho poder ha rebasado nuestra capacidad de control -e incluso de comprensión- de lo que ahora somos capaces de producir. Por consiguiente, es necesario reflexionar sobre los fines, medios y circunstancias que han de guiar la capacidad transformadora que la humanidad ha desplegado en esta nueva era, así como sus interacciones con el mundo artefactual.

Los fines intrínsecos del sistema tecnológico no son una necesidad inexorable. Los proyectos y sistemas tecnológicos pueden ser reorientados o modificados si implican riesgos mayores para la naturaleza y para la vida humana. Por ello, es necesario discutir sobre la necesidad y la posibilidad de una ética para el mundo tecnológico. Y para ello, he propuesto en Ética y mundo tecnológico (Linares, 2008) cuatro principios fundamentales de una ética que oriente a los individuos y a las instituciones sociales para analizar y evaluar los efectos del poder tecnológico: responsabilidad social, precaución, justicia distributiva y autonomía individual y comunitaria.

\section{Los anunciadores del peligro mayor}

Durante el siglo XX los fines del desarrollo tecnológico se convirtieron en un tema crucial de la reflexión ética y ontológica, a pesar de que la técnica no fue uno de los temas que más preocupó a los filósofos. Entre diversas concepciones, surgió una corriente filosófica que cuestionó el rumbo del progreso tecnológico. Algunos de los pensadores de esa corriente emprendieron diagnósticos críticos muy similares del proyecto moderno que propugnó un dominio total del ser humano sobre la naturaleza. Asimismo, advirtieron el inicio de una crisis histórica que cimbraba los fundamentos del mundo contemporáneo, pues ponía en peligro la viabilidad de muchos ecosistemas, las fuentes de recursos naturales, así como los frágiles equilibrios ambientales entre la humanidad y el planeta entero. Esta reflexión escéptica de distintos pensadores ante el progreso tecnológico fue motivada por un sentimiento común de temor ante la posibilidad de un desastre mayor, que podría ser consecuencia directa de la expansión desmesurada y acelerada del poder tecnológico, porque pondría en peligro la permanencia de los rasgos esenciales de la condición humana, e incluso la supervivencia misma de nuestra especie.

Entre esos pensadores elegí a los cinco que representan de la manera más completa una filosofía de la "sospecha" sobre el progreso tecnológico: Martin Heidegger, Jacques Ellul, Günther Anders, Hans Jonas y Eduardo Nicol. ${ }^{1}$ Ellos leyeron los signos del Apocalipsis en los logros de la razón tecnocientífica, pues

\footnotetext{
${ }^{1}$ Principales obras en orden cronológico: M. Heidegger, La pregunta por la técnica (1949); J. Ellul, La técnica o la apuesta del siglo (1954); G. Anders, La obsolescencia del hombre (1956); E. Nicol, El provenir de la filosofía (1972), y H. Jonas, El principio de responsabilidad (1979). En Ética y mundo tecnológico, dedico sendos capítulos a cada uno para analizar y evaluar sus diagnósticos.
} 
advirtieron que la realización de la utopía tecnológica implicaba el peligro de una deformación radical e irreparable de la condición humana: el ser humano dejaría de ser agente de su propio destino, a causa de la imposición de una razón tecnológica que lo constrińe a un solo fin. La pérdida de su diversidad de formas de vida y capacidad autoproyectiva se vincularía con la destrucción de su medio ambiente y con el desequilibrio entre la razón ética y la razón tecnológica. En consecuencia, estos pensadores sostuvieron la necesidad de generar una reacción moral que criticara los fundamentos del mundo tecnológico, y que revelara la ceguera e inconsciencia con las que los seres humanos se habían entregado al imperativo de la razón tecnológica, sin reparar en que quizá estaban dirigiéndose hacia la disolución de su propio ser histórico ("ser proteico", lo llamaba Nicol), de su inherente libertad para ser, en lugar de encaminarse hacia un estado de pleno bienestar y superación de todas las restricciones y sufrimientos que nos ha impuesto la naturaleza desde nuestros orígenes.

Sin embargo, los diagnósticos de estos cinco pensadores desembocan, en su mayoría, en conclusiones paradójicas y nos colocan ante la inminencia de un futuro inevitable del que no podremos escapar, ya sea por la destrucción ambiental y el agotamiento de recursos vitales para nuestra supervivencia, ya sea por las nuevas guerras tecnológicas que se ciernen sobre una humanidad que ha sobrepoblado el planeta, o ya sea por la transformación radical e irreversible de la naturaleza humana, la disolución de su razón autoconsciente, la alteración irreparable del genoma o del cerebro humanos, y por ende, de nuestras capacidades morales y auto-reflexivas. Los análisis de los cinco pensadores mencionados nos conducen a una última constatación: se aproxima nuestra hora final.

Así pues, he denominado a esos cinco pensadores los anunciadores del peligro mayor. Ellos alzaron la voz en el desierto de una sociedad que se ha obnubilado por los logros tecnológicos (muchos de ellos benéficos e indispensables, sin duda; pero también irrenunciables), y que se ha cegado ante los peligros provocados por el expansivo dominio humano sobre la naturaleza y sobre su propia condición natural. Ahora incluso comenzamos a pensar (con cierto ingenuo entusiasmo) que se ha iniciado la Era del Antropoceno, y que la naturaleza terrestre ya no volverá a ser nunca más como antes: hemos alterado y transformado prácticamente todos sus ecosistemas (Mckibben, 2003). Otros pensadores contemporáneos anuncian ya la integración y fusión del mundo de los objetos naturales, los artefactos y los humanos en una nueva "infoesfera" en la que todos los objetos se integran mediante el intercambio y procesamiento de información digital (Floridi, 2014).

Lo característico de los diagnósticos de los anunciadores del peligro inserto en el mundo tecnológico consiste en la anticipación y previsión de catástrofes que se empiezan a gestar en el presente. Las catástrofes que esos cinco pensadores anuncian son de orden ecológico, histórico, político-social e, incluso, alcanzan una dimensión ontológica; pero, ante todo, estaría en peligro el hombre mismo como ser libre y autoconsciente, capaz de autocontención y de asumir responsabilidad 
por todo el planeta. Pero sus llamados de alerta son como voces de profetas en el desierto. Pocos creen que ellos hayan tenido razón, pocos son afectos a la "heurística del temor" que propugnó Hans Jonas, porque la mayoría nos mantenemos prisioneros de lo que llamó Anders el "desfase prometeico": ya no somos capaces de imaginar aquello que estamos provocando, hemos perdido la sensibilidad moral para tomar conciencia y responsabilidad de muchos de los efectos del mundo tecnológico. Por ello, el discurso filosófico de los anunciadores no está exento de un tono apocalíptico y de una visión pesimista sobre la condición humana. Sin embargo, detrás de ese pesimismo, se revela una firme esperanza en la capacidad humana para recuperar y conservar el sentido ético de su existencia ${ }^{2}$, mientras todavía sea posible.

En una perspectiva más sosegada, el problema central para la ética del mundo tecnológico consiste en preservar, por un lado, la fuerza civilizatoria de emancipación social y de autonomía individual que los sistemas tecnológicos conllevan todavía; pero, por otro, implica generar un nuevo sentido de responsabilidad colectiva (extendida planetariamente y con alcances hacia el futuro) que reoriente y refrene los excesos negativos del poder tecnológico, tanto sobre la naturaleza como sobre la vida humana. Necesitamos generar un nuevo sentido de prudencia colectiva que sea previsora y anticipatoria, y para ello es posible disponer de las capacidades cognitivas ampliadas de las propias tecnologías informáticas y de la interrelación sistémica entre artefactos y agentes humanos. Al mismo tiempo, tendremos que distribuir de manera más justa tanto los beneficios como los riesgos del mundo tecnológico, y en esa justicia distributiva debe incluirse a muchos otros seres vivos a los cuales hemos afectado.

Pero ¿por qué y para qué poner límites al poder tecnológico, si ha reportado tan grandes beneficios generales? ¿Su derrotero no es acaso inexorable, imparable? Son justamente los rasgos ontológicos del mundo tecnológico y la particular forma de racionalidad que lo gobierna los que denotan la fuente del peligro mayor que vislumbraron los anunciadores: su expansión acelerada y su desmesura, su falta de límites, su hybris.

\footnotetext{
${ }^{2}$ La ética de anticipación de las catástrofes revela que es precisamente la indeterminación de los acontecimientos históricos que estamos atestiguando (las innovaciones tecnocientíficas y sus repercusiones en el mundo) lo que nos permite (y no obliga) pensar en la posibilidad de un escenario negativo, resultado de las acciones presentes. El plantear la posibilidad de la catástrofe no implica una concepción determinista de la historia y una negación de la libertad humana, sino todo lo contrario. Es el hacer un llamado a la responsabilidad colectiva para preservar los límites de la condición humana. El mal mayor es posible como consecuencia de nuestras propias acciones; nuestra responsabilidad consiste en anticiparlo, preverlo y evitarlo a toda costa.
} 


\section{El mundo tecnológico como entorno primario}

La técnica en su estado actual dejó de ser mero instrumentum para convertirse en un horizonte de posibilidades que configura nuestro entorno primario. Por primera vez, habitamos en un entorno de naturaleza bio-artefactual e industrializada, que está lleno de objetos artefactuales, separado y -en parte- enfrentado a la naturaleza ambiente en la que evolucionamos. Así pues, la tecnología contemporánea ha devenido mundo tecnológico. El retorno a un mundo natural sólo sería factible después de una destrucción catastrófica de la civilización tecnológica. Muchas de las utopías negativas, al estilo Mad Max, lo han anticipado en la literatura y en el cine. La transformación radical de nuestro entorno, que va del entorno natural al bio-artefactual, no implica una trasposición simple o una conversión en un mundo artificial que podamos conducir y gobernar plenamente. El mundo tecnológico subsume, desde luego, partes de naturaleza no transformada, organismos vivos y fuerzas naturales que no podemos controlar ni conducir porque no las entendemos del todo. El mundo tecnológico es un híbrido más complejo y enredado, híbrido de physis y techne, que se está desarrollando de forma sistémica y casi orgánica, de manera independiente a nuestros propios designios. No conocemos aún cómo actúan las causas que producen muchos de los efectos del mundo natural que permanecen y se articulan con los sistemas artefactuales y los sociosistemas técnicos. Nuestro actual mundo artefactual es de una complejidad mayor y se ha vuelto tan inmediato $y$, a la vez, inaccesible.

Tal como lo señalan los autores de Next Nature, (Van Mensvoort, 2011), coordinados por Koert Van Mensvoort y Hendrik-Jan Grievink, en nuestra época deberíamos reconsiderar la habitual diferencia conceptual entre naturaleza y cultura, o bien entre lo nacido y crecido naturalmente y lo producido o hecho técnicamente; ya que, por un lado, la intervención humana ha logrado transformar muchas entidades naturales y, por otro, los sistemas creados por los humanos se han vuelto tan autónomos que parecen asimilarse a las cosas que surgen naturalmente sin nuestra intervención. En lugar de seguir pensando en la clásica división aristotélica entre las cosas producidas por la naturaleza y las hechas por la técnica (Aristóteles, 2001), los autores de Next Nature nos proponen pensar ahora en la distinción entre lo que podemos dominar o controlar (técnicamente) y lo que aún no, o que está más allá de la posibilidad de ser controlado (lo verdaderamente otro). De este modo, ya no debería ser relevante, p. ej., si los organismos vivos (micro o macroscópicos) son "naturales" o han sido intervenidos biotecnológicamente, sino si podemos controlar su diseño, producción y funcionamientos, tal como podemos hacerlo, hasta cierto punto, con artefactos convencionales como teléfonos, máquinas o robots ${ }^{3}$.

\footnotetext{
${ }^{3}$ El concepto de control técnico es fundamental en las operaciones tecnológicas actuales. Controlar implica una amplia gama de acciones cognitivas y prácticas. Comprende las acciones de inspeccionar, vigilar, comprobar, supervisar, así como intervenir, regular, moderar, limitar, gobernar y, finalmente, el grado más alto de control es el dominar un objeto o sistema de objetos.
} 
Hemos podido lograr el dominio técnico de seres vivos mediante un largo proceso de domesticación que comenzó hace miles de años, que ahora accede a un nuevo nivel gracias a la ingeniería genética y la biología sintética. Podemos extraer y modificar entidades naturales como el petróleo y muchos minerales; en cierta forma se podría decir que podemos "controlar" la energía nuclear proveniente de la fisión; pero no podemos aún controlar técnicamente a muchos virus, microorganismos, fenómenos climáticos como los huracanes o tornados, o procesos biológicos anómalos como el cáncer y otras mutaciones genéticas. Del mismo modo, no podemos anticipar del todo el comportamiento de sistemas y cosas creadas por la técnica humana: virus informáticos, el tráfico de vehículos en las ciudades, o tráfico de información en la Internet. Así pues, nuestra noción de lo "natural" debe evolucionar para dar cuenta de las múltiples formas en que ahora intervenimos y modificamos entidades naturales y creamos híbridos culturales, naturoides (Negrotti, 2012) y bioartefactos (Linares \& Arriaga, 2016) de distinta índole en el mundo tecnológico contemporáneo. La distinción entre lo controlable y lo que no lo es cambiará nuestras viejas nociones (de herencia aristotélica) sobre la physis y la techne: un tomate genéticamente modificado es parte del ámbito cultural de lo controlable por la técnica (al menos eso suponen los biotecnólogos), mientras que los virus informáticos o el tráfico vehicular de las grandes ciudades pertenecerían al ámbito de una nueva modalidad de lo "natural" o de lo incontrolable por la técnica, aunque su origen pueda ser artefactual o cultural. Así que la distinción esencial entre lo técnico (artefactual o artificial) y lo natural se deslizaría hacia lo que puede ser intervenido y controlado y lo que no lo es, no importa cuál sea su origen. De este modo, se está gestando una nueva modalidad de naturaleza, una next nature; y por eso Mensvoort sostiene que ahora "real nature is not green".

Prácticamente no existe ya naturaleza que no haya sido afectada o tocada por la acción técnica humana. La naturaleza en estado natural se está desvaneciendo gracias al efecto expansivo de la intervención y dominio técnico sobre todas las entidades y ecosistemas de la Tierra (Mckibben, 2003; Purdy, 2015). Ello implica que, desde el punto de vista epistémico y estético, las diferencias, antes ostensibles, entre lo natural y lo técnico, también se difuminan. Este proceso se debe a la capacidad creciente de las biotecnologías para modificar, alterar, (re)diseñar y controlar los funcionamientos de organismos vivos, tejidos, microorganismos, moléculas biológicas, pero también a todas las tecnologías que han alterado los componentes y equilibrios químicos y físicos de los ecosistemas, desde hace más de un siglo. Se debe pues al avance de las biotecnociencias en su capacidad de intervención en la materia viva, y a las tecnologías abióticas, en su capacidad de transformación de la materia y la energía en general. La convergencia digital e informatizada que se avizora ahora se dará entre artefactos abióticos, bioar-

Por supuesto, el control técnico sólo es factible con un sistemas instrumentales cada vez más sofisticados. 
tefactos y sujetos humanos, intercambiando información digital e información genética, combinando sus materiales y estructuras mediante nanotecnologías e infobiotecnologías. Así, en el mundo tecnológico se dará, muy probablemente, la transformación onto-tecnológica de la materia, tanto inerte como viva, en nuevas formas de objetos, materiales y organismos vivos sin precedentes en la naturaleza natural.

El proceso que subyace, en todo caso, a esta mutación radical en el mundo contemporáneo es el desarrollo de la tecnociencia y de las tecnologías desde el siglo XX, como última manifestación del proyecto moderno de dominación técnica de toda la realidad natural. El objetivo principal de este proyecto global civilizatorio es el dominio e intervención tecnológica en la naturaleza, tanto biótica como abiótica. Ha consistido en un colosal proyecto de colonización técnica de la naturaleza para adecuar las fuerzas, entidades y procesos naturales a los fines humanos, para proveer los medios suficientes para el bienestar material de la humanidad, tal como lo señalaba Ortega y Gasset en su Meditación de la técnica (Ortega y Gasset, 2015). Desde la visión moderna de la tecnociencia, toda entidad natural y, en general, la naturaleza como un sistema entero se muestran como disponibles para ser materia prima de producciones de muy distinta índole; para ser transformados, alterados y adaptados a las formas y funciones que los humanos necesitan, se imaginan o desean. Este dispositivo universal de modificación técnica que compele a todas las sociedades actuales es lo que denominó Heidegger la "esencia de la técnica", o lo Gestell (Heidegger, 1995).

Así, toda entidad natural adquiere sólo un valor instrumental, mientras que su valor inherente resulta irrelevante para la visión tecno-científica. En esta dicotomía entre lo instrumental y lo natural surge la distinción onto-técnica entre lo natural y lo artefactual. ${ }^{4}$ Siguiendo la clásica concepción aristotélica entre lo generado por physis y lo producido por techne, lo natural es aquello que no ha sido intervenido por la agencia humana en ninguna de sus cuatro causas (material, formal, eficiente y final). Lo artefactual implica necesariamente que algo, por muy natural que permanezca, ha sido intervenido intencionalmente en al menos una de sus causas. Lo artefactual sólo existe y permanece por causa de los fines, propósitos y diseńos humanos, mientras que lo natural se mantiene totalmente al margen de éstos. Lo artefactual debe contener una finalidad extrínseca, asignada por los agentes humanos (el en futuro podrían ser agentes de IA); mientras que las entidades naturales (los organismos vivos, típicamente) poseen finalidades

\footnotetext{
${ }^{4}$ Nos referiremos siempre a la relación y dicotomía entre natural/artefactual y no entre natural/ artificial, como suele decirse. Lo artificial puede llegar a replicar lo natural, al menos en sus formas y funciones; mientras que lo artefactual puede ser también natural, al menos en su materialidad y fines intrínsecos, pero siempre contendrá un grado de artificialidad, pues el trabajo humano inserta en los bioartefactos funciones o fines que no son naturales, sino que simulan o imitan procesos naturales, como es el caso de la transgénesis o transferencia horizontal genética entre especies, que se produce técnicamente en los OGM replicando lo que, raramente, sucede en la interacción biológica entre especies naturales.
} 
intrínsecas o inmanentes (de ahí proviene su "valor inherente", además de que son manifestaciones de una cadena evolutiva). Sin embargo, como señala Keekok Lee:

Las más radicales y poderosas tecnologías del final del siglo XX y del XXI son capaces de producir artefactos con un nivel creciente de artefacticidad. El desafío planteado por el moderno homo faber es la sistemática eliminación de la naturaleza, tanto en el nivel empírico como en el ontológico, y de este modo, generando además una civilización narcisista (Lee, 1999, 2).

En consecuencia, el proyecto de la civilización tecnocientífica se propone convertir todo lo que existe en la naturaleza en producto artefactual; dentro de este propósito se incluye la transformación radical, en términos ontológicos, axiológicos y estéticos de todo organismo vivo en organismo vivo artefactual, es decir, en un bioartefacto, con distintos grados de artefactualidad o artefacticidad, ${ }^{5}$ dependiente del grado de conocimiento científico y control técnico que se haya logrado. Este es el plan de trabajo de las biotecnologías, las nanobiotecnología, la ingeniería genética y la biología sintética. La naturaleza se vuelve así, por medio de estas poderosas biotécnicas, un híbrido bio-artefactual, adquiere forma cultural, flexible, plástica y evoluciona a la par que nuestras representaciones culturales, fines, ideales o debates y controversias sociales. De este modo, el desafío filosófico que inquieta y causa asombro es si este avance de las tecnociencias puede conducirnos a una situación en la que se diluya por completo la diferencia entre lo natural y lo artefactual, es decir, en la que lo artefactual reemplace todo lo natural de modo irreversible. Esta es la finalidad última en la Era del Antropoceno. De este modo, tendríamos una naturaleza por completo manufacturada, nada quedaría de la naturaleza en estado natural. Esto es lo que podemos denominar una revolución bioartefactual en marcha.

\footnotetext{
${ }^{5}$ Keekok Lee utiliza el término artefacticity, "artefacticidad”. He preferido utilizar artefactualidad y bioartefactualidad. Ambos términos son adjetivos que indican la cualidad de ser productos de la técnica (arte) y no sólo de la naturaleza. Así, los términos que empleo son los siguientes: a) artefacto o artefacto abiótico, lo que está hecho por técnica y no es un organismo vivo en sí y por sí mismo; b) bioartefacto, el artefacto biótico que es el resultado de modificar técnicamente un organismo vivo, pero como tal subsiste por sí y en sí mismo como "entidad natural" ligada con otros organismos vivos y vinculado, en principio, a la evolución; d) bioartefactual, cualidad que se predica de un ser vivo tras haber sido modificado por técnica; e) bioartefactualidad, sustantivo que indica el ámbito en donde y por lo que acontece lo bioartefactual; f) bioartificial, cualidad que se predica de un artefacto biótico artificial o sin material biótico natural que imitara o replicara en sus funcionamientos básicos una entidad natural, con componentes y estructuras bioquímicos distintos (otra forma de código genético o de compuestos químicos), pero que no sería por sí mismo un organismo vivo natural ligado evolutivamente a los demás; g) bioartificialidad, sustantivo que indica el ámbito en donde acontece lo bioartificial. Esta última modalidad de bioartefactos artificiales no se ha logrado producir todavía.
} 
Lo preocupante de la tecnología moderna a largo plazo podría no ser que amenace a la vida en la Tierra como sabemos, a causa de sus efectos contaminantes, sino podría ser finalmente la humanización de toda la naturaleza. La Naturaleza, como "lo Otro", sería eliminada (Lee, 1999, 4).

\section{La racionalidad del mundo tecnológico}

La racionalidad que gobierna este mundo tecnológico es una nueva y poderosa modalidad de instrumentalidad pragmática cuyo fin es el logro de la máxima eficacia en el control y dominio de entidades naturales y sistemas sociales. Esta racionalidad se caracteriza por su capacidad para reducir la naturaleza entera -incluso al ser humano mismo- a fungir como reserva disponible para la manipulación o transformación técnica. El peligro para el ser del hombre (que vislumbraron los cinco anunciadores) reside precisamente en la ilusión de que todo cuanto nos sale al paso existe sólo en la medida en que puede ser usado o transformado técnicamente. Para este fin, la razón tecnológica ha logrado subordinar a la razón científica y ha podido desplazar a la razón teorética (científica o filosófica) del puesto central que ocupó en la historia de la civilización occidental.

La tecnología se ha convertido en el entorno necesario e indispensable para los fines pragmáticos de los seres humanos porque han devenido fines primarios, desplazando a los fines teóricos y contemplativos, a los estéticos o religiosos y a cualquier modalidad que no responde directamente a la presión de la necesidad. La nueva razón tecnológica es, como la pensó Nicol, una razón de fuerza mayor que predomina en todos los ámbitos de la actividad social. La razón tecnológica configura ahora las condiciones de la experiencia humana: la forma en que nos representamos el mundo, la forma en que actuamos en él y los criterios que utilizamos para valorarlo. No es casual que estemos obsesionados por medir, calcular, transformar, instrumentalizar, cosificar, convertir en objeto, mercancía y valor económico todo lo que encontramos en el mundo.

Ahora la racionalidad tecnológica (racionalidad pragmática uniforme y universal) se ha vuelto predominante y amenaza con extinguir a la racionalidad teorética y a toda forma desinteresada de relacionarse con las cosas. Este es el fenómeno que Eduardo Nicol denomina razón de fuerza mayor: consiste en el surgimiento de una razón unilateral que se impone por necesidad sobre las acciones libres (de ahí su fuerza mayor), que no discurre dialógicamente, que no da razones, que es indiferente a la verdad, que es violenta porque se basa en la fuerza, que supedita a los individuos y a las instituciones a una nueva forma de necesidad no natural en un mundo totalmente artefactual. Las dos formas de razón se enfrentan ahora, la reflexión teorética, desprendida de las necesidades pragmáticas y productivas, lucha por sobrevivir dando testimonio del surgimiento de la razón de fuerza mayor. Si la razón teorética declinara hasta eclipsarse (Nicol, 1972) se perdería la independencia de la razón humana y la posibilidad de una vincula- 
ción libre con la totalidad del ser mediante la búsqueda de la verdad, la belleza o la simple realidad compartida. No es casual que en el mundo tecnológico de las redes de comunicación instantánea la verdad ya no sea un referente social. En el mundo tecnológico de la virtualidad digital, cualquier cosa puede parecer verdadera, real o actual. Solo el logos dialógico de la razón que da razones es capaz de recuperar el mundo de la objetividad y de la realidad, tanto natural como social.

La racionalidad tecnológica se impone como una especie de imperativo que emplaza al ser humano a transformar y explotar la realidad natural. Este "imperativo tecnológico" implica que todo lo que puede realizarse técnicamente está moralmente justificado y que, al menos, todo lo técnicamente posible está en vías de ser realizado y debe materializarse. Ahí aparece otra vez la fuerza mayor de la razón tecnológica: nuestro destino está ya definido por ella. Desde luego que la tecnología está condicionada por una serie de factores sociales, económicos y políticos, pero la idea del "imperativo tecnológico" señala el fundamento de la racionalidad tecnológica: una implacable voluntad colectiva de poder sobre todos los objetos que están o que deben surgir en el mundo. El incremento del poder (máxima eficacia y eficiencia para convertir todo objeto en mercancía, y todo valor en valor de cambio para el mercado mundial) es el fin último al que se subordinan todas las demás condiciones y todos los fines de los agentes humanos.

\section{Artefactos, sistemas y mundo tecnológico}

Habitualmente pensamos la tecnología solamente como objeto o instrumento "a-la-mano"' que podemos usar y controlar a voluntad. Esa fue la condición general de la técnica en la historia pasada, pero ya no lo es ahora. Hasta los inicios de la modernidad, el mundo técnico se componía de instrumentos, herramientas y sistemas simples. El del presente es un mundo tecnológico y tecnocientífico que concatena múltiples sistemas técnicos, artefactos, sistemas naturales y agentes humanos, y que les confiere cada vez más agencia a todos los artefactos y sistemas técnicos. El medio que ha desarrollado para interconectarlos en la digitalización y los sistemas informáticos, pero ello sólo fue posible sobre la base de una interrelación material de los sistemas industriales y productivos que transformaron materia y energía como base mundial de nuevos sistemas tecnológicos. Los problemas más serios del mundo tecnológico se derivan de esta base material extractiva y productiva: aún se basan en la extracción y explotación de recursos de la tierra y de los mares, de la combustión de energía fósil y de su transformación en materiales de distinta índole, así como en su conversión mediante combustión en energía eléctrica. Este mundo material de alta extracción es la base del mundo tecnológico de las redes de telecomunicaciones y digitalización de toda la información.

\footnotetext{
${ }^{6}$ Esta es la concepción habitual de la técnica que Heidegger denominó "antropológico-instrumental” en su célebre La pregunta por la técnica (1949).
} 
Ahora bien, el artefacto concreto no es -por lo general- el núcleo en que se revela el problema de los fines y los valores que determinan las acciones del mundo tecnológico contemporáneo, sino precisamente el lugar en el que se ocultan. Ante los instrumentos y dispositivos del mundo tecnológico, los fines parecen claros y explícitos en la inmediatez de las acciones. Todo el problema se reduciría a elegir entre un uso adecuado y uno inadecuado de los artefactos. Tal parecería que la relación de fines y medios es transparente y que es sencillo evaluar las tecnologías y anticipar o prevenir los riesgos. Ésta ha sido la tesis de la concepción antropológico-instrumental -como la llamó Heidegger- que todavía predomina en nuestro sentido común. Dicha concepción supone que el sujeto siempre puede manejar a voluntad el instrumento y determinar su fin, y que la técnica no es más que un medio inerte y sin agencia propia para hacer algo, que está bajo nuestro dominio, que se deja de usar en cuanto se desee y que no tiene fines propios ni complejidad. Pero no es así. En gran medida, uno de los objetivos primordiales de una ética para el mundo tecnológico consiste en deconstruir esta representación instrumental de la tecnología y mostrar sus limitaciones. Los artefactos y dispositivos sólo existen, tienen función y agencia en una red de interacciones multiagenciales en el mundo tecnológico. Éste un "hiperobjeto" que no posee ya una dimensión abarcable y manipulable (tampoco comprensible del todo) como una cosa u objeto convencional y delimitado espacial y temporalmente ${ }^{7}$ (Morton, 2013). Pero es lo más concreto, y en él se despliegan fines y causas que no son visibles, ni fácilmente predecibles, ni tampoco dependen ya de la intencionalidad y de la voluntad de los sujetos humanos. El sistema del mundo tecnológico no ha cobrado vida por sí mismo, a manera de un enorme Frankenstein, sino que ha alcanzado un nivel de complejidad y de sistematicidad casi orgánicos que funciona por su propia lógica e impulso compeliendo a los sujetos humanos a subordinarse al mundo tecnológico.

Como seńalamos, ya se avizora como el siguiente paso necesario la interconexión y comunicación entre artefactos abióticos y agentes humanos mediante tecnologías informáticas (Schwab, 2016), que acelerará la sistematicidad y acción orgánica del mundo tecnológico. Por ello, la tecnología contemporánea es mucho más que un conjunto de instrumentos y objetos técnicos, es más bien un sistema global en expansión (como lo pensó Ellul); es una red de sistemas técnicos ${ }^{8}$ que interactúan incrementando la complejidad de las interrelaciones y el

\footnotetext{
${ }^{7}$ De acuerdo con Timothy Morton (2013), los "hiperobjetos" se caracterizan por su viscosidad o elasticidad, su no localidad o dispersión espacial, su "ondulación temporal” o persistencia difusa, su discontinuidad en fases, y su interobjetividad o interacción con muchos otros objetos. Los hiperobjetos pueden ser fenómenos naturales, sociales o sistemas artefactuales.

${ }^{8}$ El concepto de "sistema técnico" ha sido acuñado por Miguel Ángel Quintanilla en Tecnología: un enfoque filosófico, Fundesco, Madrid, 1989. (2a ed. en Fondo de Cultura Económica, México, 2017). Un sistema técnico comprende artefactos, materiales, energía, agentes humanos (operarios, diseńadores, usuarios, etc.), conocimientos especializados, técnicas, acciones y procesos operativos, valores, propósitos y fines determinados.
} 
alcance global de sus efectos sobre la naturaleza y la sociedad, tanto en el espacio geográfico como en el tiempo físico e histórico. Sus efectos y consecuencias son acumulativos y entrópicos, algunos irreversibles, pero muchos de ellos prácticamente imprevisibles. Por ello, la complejidad epistémica para comprender, evaluar y calcular o medir las causas y efectos del mundo tecnológico ha aumentado más allá de nuestras capacidades cognitivas naturales. Mucha ayuda requerimos ahora de los sistemas y dispositivos informáticos que ya efectúan la minería de datos masivos (big data) que genera e impulsa a los sistemas tecnológicos. Pero ese mundo que hemos construido nosotros con nuestras acciones y decisiones no está ya al alcance, ni en términos cognitivos ni en términos prácticos. Una ética del mundo tecnológico debe comprender cómo actúa la tecnología en tanto emplazamiento hiperobjetual y como sistema-mundo, mediante un imperativo de acción que se manifiesta en los grandes sistemas tecnológicos, por ejemplo, en la red de telecomunicaciones y tecnologías de la información, o en las cadenas productivas industriales, su distribución y comercialización mundial y su desecho ambiental o su incorporación al cuerpo humano.

Ante esta dimensión sistémica (no instrumental) del mundo tecnológico, que no es evidente en los objetos técnicos inmediatos, la filosofía de nuestro tiempo se enfrenta al desafío de discernir cuál es el sentido y el fin último del mundo tecnológico; es decir, esclarecer la finalidad del despliegue de una voluntad de poder que conmina al ser humano a realizar y desarrollar todo lo técnicamente posible, traspasando los límites de la cultura, la sociedad y la naturaleza misma. ${ }^{9}$

\section{Las propiedades del mundo tecnológico que impelen a poner lími- tes éticos}

Una concepción ontológica del mundo tecnológico debe delimitar cuáles son los rasgos esenciales y las propiedades emergentes de nuestro mundo actual, pues estos conceptos constituyen la base para un cuestionamiento ético más efectivo y que no se reduzca a un dilema personal o local, sino que comprenda las dimensiones planetarias de lo que está en juego.

\footnotetext{
${ }^{9}$ La racionalidad que domina en el mundo tecnológico supone que la realidad natural (incluida la humana) es modificable de acuerdo con los fines que nosotros nos propongamos, pues la naturaleza puede ser reconfigurada a nuestro antojo. El mundo tecnológico no tiene límites, tanto en el sentido de su expansión geográfica como en el de sus capacidades de acción, pues en él todo está en un flujo evolutivo, nada tiene consistencia y estructura fija, la naturaleza y el hombre mismo pueden ser reconfigurados y reconstruidos, todo es técnicamente posible. La liquidez de la ontología tecnológica es un principio de neutralización del valor de todas las entidades, naturales o artefactuales, equiparándolas como objetos-instrumentos-mercancías. Por eso, Anders comentaba que en el mundo tecnológico predominaba una nueva forma de "nihilismo" axiológico: todo vale igual o no vale si no puede ser transformado, usado y convertido en objeto técnico con valor en el mercado mundial.
} 
1. Artefactualidad y artificialidad. El mundo tecnológico no es natural; la naturaleza ha quedado subsumida, ha sido transformada en el entorno tecnológico y convertida o subsumida en sistemas artefactuales y artificiales. ${ }^{10}$

2. Racionalidad pragmática y económica. En el mundo tecnológico todo objeto natural puede ser convertido en artefacto y todo artefacto en mercancía $\mathrm{u}$ objeto con valor de cambio, potenciando su valor de uso. Su finalidad última es la búsqueda de la máxima eficacia y eficiencia operativas en todos los órdenes de la praxis humana. Sin embargo, en el mundo tecnológico suelen entrar en conflicto los valores y fines técnicos con los económicos del mundo capitalista. Hemos de señalar que el mundo tecnológico actual está completamente subordinado al mundo del capitalismo globalizado.

3. Emplazamiento artefactual de la naturaleza y de los seres vivos (bioartefactualidad). El mundo tecnológico se funda en una disponibilidad universal de todo ente para ser reducido a objeto de transformación y manipulación tecnológica, para convertir toda la naturaleza, en sus partes y en sus sistemas, a los organismos vivos y a sus componentes bioquímicos y celulares, genéticos y genómicos, en un artefacto o producto tecnológico, patentable y comercializable, antes de ser usado efectivamente.

4. Autocrecimiento progresivo y dimensión global de sus alcances, tanto en el espacio como en el tiempo. Este autocrecimiento conlleva una forma relativa de autonomía con respecto a los sistemas sociales (económicos, políticos, éticos). El autocrecimiento es la base de la ideología del progreso tecnológico y del imperativo de innovación artefactual. Este imperativo de innovación no sólo surge de las necesidades sociales, sino de las necesidades de crecimiento de los capitales y de los mercados. Una consecuencia de esta expansión geográfica es la uniformidad de valores, formas de vida y criterios culturales. El mundo tecnológico es un mundo homogeneizado y normalizado.

\footnotetext{
${ }^{10}$ Conviene distinguir entre artefactualidad y artificialidad. La primera expresa la transformación de cualquier objeto, materia o proceso en un artefacto u objeto técnico, transformación que implica, al menos, la modificación de alguna de sus causas y la introducción de una finalidad o función asignada por los humanos. En cambio, la artificialidad implica la construcción de artefactos que simulan, imitan, replican o sustituyen objetos, procesos y sistemas naturales, pero que están hechos de materiales no bióticos, tales como corazones artificiales, piernas o brazos artificiales, perlas artificiales, textiles artificiales, dientes artificiales, inteligencia artificial, respirador artificial, sabores artificiales, etc. Lo artificial también se denomina sintético y normalmente las prótesis son artefactos artificiales. El siguiente paso que postula la biología sintética es la construcción de bioartefactos artificiales, hechos con materiales, componentes y estructuras bioquímicas (genéticas, celulares y moleculares) no naturales o sin precedentes en la naturaleza, pero que repliquen o imiten la forma en que funcionan, se desarrollan y se reproducen los organismos vivos.
} 
5. Interconexión compleja, orgánica y sistémica. El mundo tecnológico es un sistema de creciente complejidad por efecto de la interconexión intencional o accidental entre los diversos y distintos subsistemas tecnológicos. La interconexión ha avanzado en dos dimensiones. Primeramente, interconectando mediante dispositivos informáticos a los artefactos abióticos entre sí; luego a éstos con los agentes humanos. Un tercer nivel será la interconexión informática entre artefactos, humanos y bioartefactos informatizados. En una primera dimensión es información física, mediante soportes electrónicos, lo que se comunica y procesa. La segunda dimensión es el intercambio de información genética y biológica entre organismos vivos (incluyendo, desde luego, a los humanos). La tercera dimensión de interconexión podría ser la combinación de información física y biológica en unos niveles moleculares o atómicos, a nivel bio-nanotecnológico. Las interconexiones construyen nuevos sistemas tecnológicos de mayor alcance y penetración, tanto en las estructuras materiales de objetos $\mathrm{u}$ organismos como en las redes mundiales de interacción de los sistemas.

6. Riesgo generalizado pero difuso y peligro de colapsamientos sistémicos. Vivimos ahora en una "sociedad del riesgo" como la caracterizó Ulrich Beck (1998), porque el poder tecnológico puede provocar daños irreversibles a la naturaleza, a los organismos vivos y a la vida humana. Los sistemas pueden colapsar y, sin embargo, seguir siendo funcionales, mientras no se agoten las fuentes de energía o de materia, así sucede ya con ecosistemas o con sistemas urbanos. Los riesgos aumentan, y se complican con los efectos del cambio climático global y la pérdida de biodiversidad, pero su percepción social se vuelve difusa y ello se deriva de los caracteres que he mencionado previamente -centralización y dependencia creciente, autocrecimiento, interdependencia sistémica. La posibilidad de que sucedan accidentes catastróficos en los sistemas tecnológicos es cada vez mayor, debido a la interdependencia, la dimensión global, la centralización y el encadenamiento progresivo. Chernobyl fue sólo un ejemplo del riesgo tecnológico mayor en el mundo contemporáneo. Si las catástrofes tecnológicas son posibles (aunque parezcan poco probables), ello nos obliga racionalmente a anticipar y prever lo peor. El riesgo se ha incrementado, además, en la medida en que las decisiones tecno-políticas se concentran en unas cuantas personas, ${ }^{11}$ pues los sistemas tecnológicos están centralizados y dependen de sistemas artefactuales de monitoreo y todavía de agentes humanos que deben tomar decisiones cruciales.

\footnotetext{
${ }^{11}$ Los grandes riesgos inminentes en las tecnologías fósiles, nucleares, químicas, informáticas, genéticas y bioquímicas, neurológicas o nanotecnológicas tienen ahora un potencial alcance global que se extendería en el tiempo, por lo cual no son compensables en términos económicos. No habría prima de seguro que cubra la destrucción que provocarían esas tecnologías, si llegaran a fallar (Beck, 1998).
} 
7. Autonomía relativa de los sistemas tecnológicos. El mundo tecnológico parece progresar y crecer de modo autónomo. Por ello, el desafío para la ética y la política de nuestro tiempo consiste en establecer bases para el control y la evaluación social de las tecnologías, mediante una nueva cultura de valores éticos y de acciones co-responsables entre científicos, tecnólogos y el resto de la sociedad. La tecnología y la tecnociencia no pueden dotarse a sí mismas de fines y criterios éticos. Es la sociedad entera la que debe evaluarlas, conducirlas y orientarlas conforme a principios y reglas fundados en los intereses vitales de la humanidad, y mediante procesos de deliberación y decisión más abiertos que involucren a todos los usuarios y posibles afectados.

La autonomía de los sistemas tecnológicos no sólo es ética y política, constituye por sí misma un desafío epistémico. En la medida en que crece el poder de intervención y acción en el mundo tecnológico, los efectos y las consecuencias (tanto las planeadas como las imprevistas) se han extendido geográficamente a todo el planeta y temporalmente hacia el futuro remoto.

Un nuevo poder social, surgido de la conciencia ética de los rasgos que caracterizan al mundo tecnológico, es necesario y posible para enfrentar las consecuencias negativas del poder tecnológico, sin tener que renunciar a sus innegables logros y sin restringir la libertad de investigación tecnocientífica.

\section{Los principios de la ética para el mundo tecnológico}

A partir de una concepción ontológica del mundo tecnológico podemos formular una serie de principios básicos para una ética que enfrente sus consecuencias, desafíos sin precedentes y riesgos difíciles de predecir. Pero ello implica la necesidad de cuestionar y sobrepasar ciertos límites de la tradición ética occidental. De acuerdo con Hans Jonas (1995), las éticas habidas hasta ahora se fundaban en dos premisas que impiden afrontar cabalmente las nuevas condiciones de la acción tecnológica globalizada: a) la condición humana es fija e inmutable, b) el alcance de la acción humana y, por consecuencia, de la responsabilidad tiene corto alcance en el espacio y en el tiempo. Desde mi punto de vista, antropocentrismo, etnocentrismo y limitado alcance espaciotemporal ${ }^{12}$ son los tres rasgos que han agravado el "desfase prometeico" (Anders, 2011) que se da entre un poder

\footnotetext{
${ }^{12}$ También podemos agregar androcentrismo, pues se ha vuelto más evidente en nuestra época que en muchos de los debates y controversias tecnológicas hay un problema de equidad de género. Actualmente, tanto el desarrollo de las tecnociencias como las decisiones cruciales sobre la innovación y regulación tecnológicas permanecen en manos de varones. La poca prudencia y la sobrevaloración de riesgo-oportunidad para el desarrollo tecnocientífico suelen identificarse como valores más masculinos que femeninos. ¿Qué pasaría con una tecnociencia más feminizada, más empática con la naturaleza y los organismos vivos, más prudente y equilibrada, con menos afanes de dominio y de crecimiento exponencial de la producción y extracción de recursos naturales?
} 
tecnológico que se expande de modo ilimitado y nuestras concepciones e instituciones éticas y políticas, que están desarticuladas y que no responden a las nuevas condiciones históricas. En particular podemos señalar:

- El antropocentrismo. Nuestra tradición ética no ha incorporado como objetos de consideración moral a los otros seres vivos, así como al entorno natural en su conjunto como "pacientes morales" que reciben los efectos de la acción humana. En la más pura tradición kantiana, sólo lo humano sigue siendo fuente de deber moral para la mayoría. Al mismo tiempo, seguimos pensando que la "naturaleza" humana es fija e invulnerable, que el ser humano no puede ser objeto de radical transformación tecnológica. No obstante, uno de los fines tecnológicos más desafiantes es la superación de la condición humana, el transhumanismo tecnológico.

- El etnocentrismo. La tradición ética occidental ha priorizado en su consideración moral sólo a un grupo cultural que se supone homogéneo (el mundo occidental, cristiano, "blanco", que emplea la razón tecnológica y que cree ciegamente en las bondades del mercado capitalista mundial y en las democracias representativas, ahora telegobernadas por élites tecnocráticas). De este modo, el proyecto ilustrado de la razón tecnológica ha implicado también el proyecto de dominio de una cultura sobre las demás pretendiendo imponer "sus" valores universales. El resultado ha sido un dominio violento y, en ocasiones, genocida y ecocida. El etnocentrismo tecnológico - que ha sido fundamentalmente eurocentrismo y occidentalismo, revestidos de tecnoidolatría y fe ciega en el progreso tecnológico- ha impedido alcanzar una visión verdaderamente universal de los principios éticos elementales que serán necesarios para enfrentar los nuevos desafíos globales. Los prejuicios etnocéntricos han sido análogos y conjuntos a los prejuicios de "especie" (que justificaban el dominio antropocéntrico sobre otros animales): racismo, esclavismo, antisemitismo, etc. La ética para el mundo tecnológico debe afirmarse en un paradigma que reconozca la comunidad (biocultural, genética) y, a la vez, la diversidad (histórica y cultural) de la condición humana. Debe rescatar y proteger saberes tradicionales y evitar la biopiratería de los bienes técnicos y bioculturales de muchas comunidades; debe evitar la destrucción ambiental y la extracción excesiva de recursos naturales o expoliación de territorios en donde habitan las comunidades ancestrales o que anteceden a la modernidad tecnológica. ${ }^{13}$

\footnotetext{
${ }^{13}$ Se han dado muchos problemas y debates sobre los proyectos tecnológicos que, avalados por los gobiernos, expropian o permiten la explotación de recursos naturales en sitios en donde habitan comunidades tradicionales. Así sucedió en México con el caso de Wirikuta, sitio sagrado de los indios huicholes (en Nayarit, noroeste de México), que fue concesionado a empresas extranjeras para la extracción masiva de minerales. Véase: https://es.wikipedia.org/wiki/Wirikuta
} 
- La limitada visión de los alcances espaciotemporales de las acciones humanas. La tradición ética occidental ha funcionado como una ética de la proximidad, tanto espacial como temporal. Hans Jonas (1995) señala que esta concepción puede continuar aplicándose al ámbito de las relaciones interpersonales, pero no al mundo tecnológico en el que las acciones humanas se integran en un complejo sistema y, por ende, tienen alcances remotos, afectando a las generaciones futuras de seres humanos y a la totalidad de la biosfera. Por primera vez en la historia, los humanos del futuro deben contar con sus intereses de supervivencia, tanto como los del presente. Al mismo, tiempo "una ética cara al futuro" implica construir una ética que haga valer la herencia que nos legaron los antepasados y que repare los daños a aquellos que ya han sido víctimas del mundo tecnológico. Dichas víctimas no han sido solo humanas, miles de especies se han extinguido o están seriamente amenazadas por el desarrollo implacable del poder tecnológico.

Basándonos en las tesis de los anunciadores del peligro mayor, la ética para el mundo tecnológico puede argumentar que existen ya signos en la situación actual que implicarían la posibilidad de distintos escenarios catastróficos. Si existe la posibilidad de ese peligro mayor, entonces los nuevos imperativos morales enunciarán los principios básicos para asegurar la continuidad de la existencia de una humanidad capaz de responsabilidad, una humanidad que preserve su esencial condición ética. Pero ello solo es posible si lo que queda del mundo natural es protegido y conservado. El mundo tecnológico no puede acabar de engullir a todos los ecosistemas ni continuar agotando los recursos naturales ni acelerando la extinción de especies y la pérdida de biodiversidad. Agua, tierra, cielo, organismos vivos son los nuevos objetos de protección de la responsabilidad colectiva, una responsabilidad precautoria y que sea capaz de actuar con justicia entre los humanos, así como entre los humanos y el resto de los seres vivos.

En particular, una tarea de la ética para el mundo tecnológico se concentra en la crítica del antropocentrismo ontológico y moral de la tradición occidental: los límites de la comunidad moral no son idénticos a los límites de la especie humana. Todos los seres vivos individuales y los colectivos conformados por ellos merecen consideración moral porque poseen un valor intrínseco (no instrumental, no técnico), y están al cuidado de nuestra responsabilidad precisamente porque nuestras acciones tecnológicas pueden poner en peligro su existencia. La crítica del antropocentrismo tecnológico no implica negar la singularidad e irreductibilidad ética de nuestra especie: sólo los seres humanos somos agentes morales, capaces de obligación y de responsabilidad ética. Por el contrario, subraya nuestra singularidad ontológica: mientras la razón tecnológica de fuerza mayor no oblitere nuestra razón ética y nuestra capacidad de conciencia y empatía con todo lo vivo, estamos obligados a respondes y reaccionar para salvar lo que queda del mundo natural. 
Sin embargo, nuestra tradición ética requiere una transformación radical que debe ir en el sentido de extender el campo de consideración moral más allá de los seres humanos, pero sin apostar por un biocentrismo superficial e igualitarista que propugne un valor idéntico para toda forma de vida. Se trataría, más bien, de buscar una posición intermedia y quizá provisional (un antropocentrismo moderado y un biocentrismo jerarquizado), pues debe ser revisada constantemente por un diálogo global e intercultural. Entre las decisiones más complicadas están el cómo intervenir o actuar para proteger a otros seres vivos y a ecosistemas enteros, porque toda intervención técnica tendrá efectos. Además, para los organismos vivos que han sido transformados en bioartefactos se imponen obligaciones distintas que para los organismos vivos (especialmente, plantas y animales) que no han sido transformados, ni dominados ni incorporados al mundo tecnológico, pues deben ser preservados en reservas naturales. Estos son principios básicos de justicia ambiental entre seres vivos que debe poner en práctica la ética para el mundo tecnológico. Como una ética de autocontención del poder tecnológico (Riechmann, 2004), el enorme desafío en el mundo tecnológico será limitar los excesos de ese poder y desactivar el ritmo de producción, extracción, explotación y destrucción de la naturaleza. Mucho más problemáticas serán las necesarias acciones de remediación y recuperación ecológica de los ecosistemas. En dichas acciones es necesaria una intervención técnica que debe ser prudencial y con objetivos muy acotados. ${ }^{14}$

Los principios de una ética para el mundo tecnológico deben estar en correlación y en confrontación constante, pero a condición de que no se eliminen unos a otros, manteniendo un nivel mínimo en la acción individual y colectiva. Estos principios tendrán como finalidad revitalizar un conjunto de valores universalizables para reforzar los vínculos éticos de la humanidad con su mundo, tanto natural como artefactual. La racionalidad tecnológica puede ser contenida y reorientada tomando sus propios criterios de eficacia operativa, así como sus recursos y dispositivos informáticos y cognitivos, productivos y reconstructivos del mundo natural y social.

Mi hipótesis consiste en que es posible alcanzar la formulación de principios globales y transculturales que fundamenten criterios de acción tecnocientífica válidos para toda la humanidad, reconociendo y respetando la pluralidad histórico-cultural de concepciones y prácticas morales existentes, así como saberes tradicionales y valores locales. Y ello es posible si se aprovechan las características globales, sistemáticas y de alcances extendidos de las acciones e interconexiones del mundo tecnológico. Los rasgos negativos que los críticos del mundo tecnológico seńalaron podrían ser revertidos, pues contienen la potencialidad para

\footnotetext{
${ }^{14}$ Por ejemplo, tendría sentido revivir mediante biotecnología especies recientemente extintas si sus funciones ecosistémicas son esenciales, pero no intentar revivir especies que se extinguieron hace millones de años o virus y bacterias que han sido erradicados por su efecto peligroso y letal para la salud humana.
} 
soportar un conjunto de valores universales y diferenciables que posean eficacia práctica, siempre y cuando sea posible establecer acuerdos sociales e internacionales para la evaluación y regulación efectiva de los sistemas tecnológicos.

\section{Conclusión}

Para concluir esta síntesis, comentaré los principios de una ética para el mundo tecnológico.

a. Principio de responsabilidad que determina qué es lo que estamos obligados a cuidar y preservar: la integridad y dignidad de la vida humana en primer término; es decir, el objeto primordial de la responsabilidad es una vida humana que conserve sus caracteres de conciencia ética y de acción libre, de finitud (natalidad-mortalidad), vulnerabilidad, unidad y comunidad biológico-genética. La primera obligación moral es, pues, asegurar la existencia de seres morales con capacidad de responsabilidad. Por ello, es problemático el análisis y evaluación de antropotecnologías eugenésicas o transhumanistas.

La responsabilidad implica el desarrollo del conocimiento científico para prevenir y anticipar los efectos negativos de la intervención tecnológica, así como la difusión más extensa posible de lo que se sabe sobre los riesgos y daños, para que la sociedad tome decisiones mediante procedimientos democráticos que involucren a los directamente afectados. El principio de responsabilidad implica un cuestionamiento profundo de nuestras instituciones y prácticas democráticas, así como del individualismo y fragmentación de la vida social. Si el peligro que acecha es común (la crisis ecológica global), la respuesta ética debe ser coordinada y los riesgos deben ser repartidos equitativamente. Si el mundo tecnológico es sistémico y global, la respuesta ético-política debe ser también sistémica y globalizada.

b. Principio de precaución que indica que, ante la posibilidad de un peligro que se funda en previsiones razonables, aunque no existan pruebas científicas contundentes, y si el posible daño es incalculable o superior al beneficio esperado, es preciso revisar la acción tecnológica planeada, detenerla, modificarla o inhibirla. El principio de precaución no rechaza todo riesgo y todo tipo de daño que sea efecto de una acción tecnológica, ante todo, porque muchos de los efectos son imprevisibles; sino que indica que el daño o mal esperado, con razones fundadas, no puede ser incalculable u ostensiblemente mayor al beneficio proyectado. Los dańos y riesgos deben mantenerse en un nivel racionalmente aceptable, siempre y cuando no impliquen una distribución injusta entre la sociedad.

c. Principio de protección de la autonomía individual y comunitaria. Las acciones tecnológicas deben proteger, favorecer y potenciar la autonomía 
individual para que cada sujeto decida de modo responsable sobre su cuerpo y su propia vida, sin afectar ni coartar la autonomía y la libertad de otros. La autonomía individual puede colisionar contra el principio de responsabilidad. Las posibilidades biotecnológicas de transformación de la corporalidad serían un caso ejemplar. La modificación biotecnológica del cuerpo sería un derecho individual, pero al mismo tiempo, podría poner en riesgo algún rasgo de la condición humana; por ello, esta intervención tecnológica sobre el cuerpo y la mente humanos debe ser muy prudente, $y$ avanzar primeramente en acciones eugenesia negativa para curar enfermedades y discapacidades e igualar las oportunidades de desarrollo. Asimismo, el principio de autonomía comunitaria implica reconocer el derecho de distintas comunidades a utilizar otros medios o a rechazar, con razones fundadas, sistemas e innovaciones tecnológicas que afecten sus territorios, recursos naturales o culturas materiales. La pérdida de diversidad bio-cultural (como los métodos de siembra y cultivo o técnicas terapéuticas y medicinales que utilizan recursos naturales) es también una grave disminución de patrimonio natural y biológico.

d. Principio de justicia distributiva de los beneficios tecnológicos, pero también de los riesgos. No sólo significa que cada vez más personas se beneficien del desarrollo tecnológico y que disminuya la brecha en los niveles de vida entre los países ricos y los países pobres, sino también que los riesgos sean razonables y compartidos social e internacionalmente. Los problemas ecológicos afectan a todo el mundo, pero los riesgos y los dańos se incrementan para los más vulnerables en la escala socioeconómica.

Los principios éticos señalados son solamente las bases axiológicas para asegurar la continuidad de una humanidad capaz de responsabilizarse por los efectos de su poder tecnocientífico, una humanidad que preserve su esencial condición ética, que sea capaz de responsabilizarse por el entorno natural del que depende para sobrevivir, así como por la herencia biocultural y tecnocientífica que legará a las futuras generaciones.

\section{Referencias bibliográficas}

Anders, Günther (2011). La obsolescencia del hombre, vol I. Valencia: Pre-textos. Aristóteles (2001). Física. México: UNAM.

Beck, Ulrich (1998). La sociedad del riesgo. Barcelona: Paidós.

Ellul, Jacques (1954). La Technique ou l'enjeu du siècle. París: Armand Colin.

Floridi, Luciano (2014). The 4th Revolution: How the Infosphere is Reshaping Human Reality. Oxford: Oxford University Press. 
Heidegger, Martin (1995). La pregunta por la técnica. En Conferencias y artículos. Barcelona: Ediciones del Serbal.

Jonas, Hans (1995). El principio de responsabilidad. Barcelona: Herder.

Lee, Keekok (1999). The Natural and the Artefactual. The Implications of Deep Science and Deep Technology for Environmental Philosophy. Maryland: Lexington Books.

Linares, Jorge E. (2008). Ética y mundo tecnológico. México: FCE/UNAM.

Linares, Jorge E. y Arriaga, Eelena (eds.) (2016). Aproximaciones interdisciplinarias a la bioartefactualidad. México: UNAM.

Mckibben, Bill (2003). The End of Nature. Humanity, Climate Change and Natural World. London: Bloomsbury.

Morton, Timothy (2013). Hyperobjects: Philosophy and Ecology after the End of the World. Minneapolis: University of Minnesota Press.

Negrotti, Massimo (2012). The Reality of the Artificial. Nature, Technology and Naturoids. Berlin: Springer.

Nicol, Eduardo (1972). El porvenir de la filosofía. México: Fondo de Cultura Económica.

Ortega y Gasset, José (2015). Meditación de la Técnica. Madrid: Biblioteca nueva.

Purdy, Jedediah (2015). After Nature: A Politics for the Anthropocene. Cambridge, MA: Harvard University Press.

Riechmann, Jorge (2004). Gente que no quiere viajar a Marte. Ensayos sobre ecología, ética y autolimitación. Madrid: Libros de la Catarata.

Schwab, Klaus (2016). The Fourth Industrial Revolution. Geneva: World Economic Forum.

Van Mensvoort, Koert (ed.) (2011). Next Nature. Amsterdam-Barcelona: Actar. 